\title{
LOGÍSTICA REVERSA DE PALETES - UM ESTUDO DE CASO
}

\author{
Mario Fernando de Mello ${ }^{1}$ \\ Mauricio Antônio de Anunciaçãó ${ }^{2}$
}

\begin{abstract}
Resumo: A evolução da logística reversa nos últimos anos tem levado as empresas reorganizarem a necessidade de retorno de bens, materiais ou equipamentos em seus processos produtivos. Para garantir todo este processo até seu ponto de origem, a logística reversa está passando por um período de relevantes mudanças. Em ascendência o tema faz com que as empresas busquem aperfeiçoar todos os seus processos reversos objetivando uma redução de custos e cuidados com o meio ambiente com estes procedimentos. Este estudo busca analisar o processo reverso da utilização de paletes em uma empresa de grande porte do setor industrial de alimentos localizada no norte do estado do Rio Grande do Sul. Inicialmente foram explorados conceitos de diversos autores sobre logística reversa e custos para dar base ao presente estudo Posteriormente, foram verificados os processos de logística reversa da empresa para em seguida analisar a entrada, triagem, conserto e descarte do equipamento chamado palete. Após análise desses dados foram verificados os custos com cada processo reverso e sugeridas algumas ações de melhorias para redução destes custos. O tema é de grande relevância para as empresas poderem identificar qual a origem de seus custos com a logística reversa, e também melhorar sua imagem em relação às ações ambientais fazendo com que se tornem mais competitivas e atuantes com práticas econômicas e sustentáveis.
\end{abstract}

Palavras Chave: Logística Reversa, Palete, Custos.

\begin{abstract}
The evolution of reverse logistics in recent years has led companies to reorganize their needs regarding the return of goods, materials or equipment in their production processes. To ensure this process until its point of origin, reverse logistics has been going through a period of significant changes. The issue has led companies to seek for ways to optimize all their reverse processes aiming at reducing costs and taking care of the environment with these procedures. This study analyzed the reverse process of using pallets in a large company in the food industry located in northern Rio Grande do Sul. Firstly, we explored concepts of different authors about reverse logistics and costs to be used as a basis in this study. Secondly, we verified the reverse logistics processes of the company and then analyzed the input, sorting, repairing, and disposing of the equipment called pallet. Finally, after the analysis of data, we checked the costs of each reverse process and suggested some actions focusing on the improvement to reduce these costs. The topic studied is of great importance for the companies to identify the origin of their reverse logistics costs and to improve their image regarding environmental actions, making them more competitive and active using economic and sustainable practices.
\end{abstract}

Keywords: Reverse Logistics, Pallet, Costs.

\footnotetext{
${ }^{1}$ Departamento de Engenharia de Produção, Universidade Federal de Santa Maria e Universidade Luterana do Brasil. E-mail: mariofernandomello@yahoo.com.br

${ }^{2}$ Universidade Luterana do Brasil campus Carazinho. E-mail: mauricio.carazinho@yahoo.com.br
} 


\section{INTRODUÇÃO}

Para as organizações conquistarem novos espaços no mercado muitas têm se utilizado da chamada logística empresarial. Disputar mercados somente com preços, qualidade e prazos já não é mais um diferencial competitivo uma vez que muitas organizações estão trabalhando desta forma. É preciso ampliar esta visão em termos de práticas empresariais percebidas pelos clientes e sociedade, como o uso da logística reversa e o cuidado com o meio ambiente.

Para Razzolini Filho (2009) o conceito de logística empresarial tem pouco tempo de prática no país e as exigências para recuperar o tempo perdido são muitas. Tendo em vista a ascensão do cenário logístico no país até mesmo nos meios de comunicação, bem como em todos os meios de transporte, faz-se necessário avaliarmos a questão da logística reversa nas empresas e o quão importante esta é para o nosso ciclo de reaproveitamento ou reuso de materiais.

A logística reversa quando bem administrada pelas organizações, aponta opções para que as mesmas consigam não só reduzir custos, mas também minimizar os impactos ambientais. Na visão atual da logística, com base na evolução dos conceitos as empresas estão percebendo a importância da preocupação com as questões da logística reversa, considerando que o desenvolvimento sustentável é possível.

A empresa estudada atua na área industrial de alimentos e através de seu depósito fabril, estoca e expede produtos de gêneros alimentícios.

Se para as organizações a logística se dá quando o seu produto chega ao destino final na hora certa e no lugar certo atendendo o consumidor final, da mesma maneira a logística reversa faz-se importante para garantir o retorno, reuso, ou até mesmo descarte de alguns materiais com o destino correto.

Com o crescimento populacional e industrial percebido em nosso país nos últimos anos, Razzolini Filho (2009) ressalta que o cuidado com as questões ambientais e ecológicas também crescem.
Porém, a preocupação é que as organizações industriais têm empregado a cada dia uma quantidade maior de embalagens e produtos descartáveis, demostrando ainda pequena preocupação com a reciclagem.

O objetivo deste trabalho é identificar os processos reversos na logística de paletes, analisar os custos dos processos reversos de coleta, triagem conserto e descarte de paletes e como reduzir estes custos, uma vez que existe a necessidade da logística reversa de tais materiais. A partir do levantamento desses dados, este estudo sugere algumas ações para redução dos custos com a reutilização desses equipamentos necessários ao transporte de mercadorias.

É um problema e um desafio para a ciência da gestão da produção integrar a produtividade com a sustentabilidade. É fundamental essa integração, e, nesse sentido empresas com grande uso do equipamento estudado neste caso ou equipamentos semelhantes podem contribuir com o meio ambiente reutilizando os mesmos. Sendo assim, a sustentabilidade, antes uma categoria restrita a padrões ambientais tornou-se uma nova palavra no mundo dos negócios. A sustentabilidade ganhou ímpeto neste contexto de temas emergentes.

\section{METODOLOGIA}

O presente trabalho está divido em duas partes. Na primeira parte é feita uma revisão bibliográfica de pontos que servem de embasamento para a análise dos resultados. $\mathrm{Na}$ segunda parte são demonstrados os resultados provenientes da pesquisa efetuada na empresa selecionada. Por solicitação da empresa, sua identificação não foi revelada.

A pesquisa, do tipo estudo de caso é recomendada por Yin (2010) para uma investigação empírica que trata um fenômeno contemporâneo em profundidade e em seu contexto de vida real. A pesquisa foi feita em uma empresa de grande porte, situada no norte do Estado do Rio Grande do Sul, que possui atividade de indústria de produtos alimentícios além de depósito desses 
produtos. Foram levantadas questões da sua logística reversa, procurando identificar e analisar todos os processos que envolvem a logística reversa de paletes.

Os dados foram pesquisados e analisados no período de abril de 2013 a setembro de 2013. O levantamento dos dados aconteceu no setor responsável pelo controle de recebimentos dos paletes. Foram criadas planilhas para serem preenchidas por dois trabalhadores do setor. Após o período determinado para a coleta dos dados que foi de abril 2013 a setembro de 2013 os dados foram agrupados e analisados pelos pesquisadores. Com auxilio do aplicativo Microsoft Excel ${ }^{\circledR}$ os resultados estão demonstrados no capítulo 4 deste trabalho.

\section{REVISÃO BIBLIOGRÁFICA}

\subsection{BREVE HISTÓRICO DA LOGÍSTICA}

A logística tem uma história de centenas de anos, porém como marco histórico mais recente, a Segunda Guerra Mundial teve papel preponderante no desenvolvimento da logística, uma vez que exigiu das nações envolvidas no conflito o desenvolvimento de atividades logísticas que garantissem a manutenção das tropas. Após a guerra a logística deixou de ser preocupação exclusiva no ambiente militar e passou a fazer parte dos processos industriais e comerciais de empresas que buscavam crescimento e competitividade no mercado.

Eram necessárias atividades como abastecimento de linhas de produção das fábricas, bem como o processo de produção de veículos, equipamentos, armas, alimentos e remédios entre outros. A distribuição de todos esses produtos nas linhas de combates exigiu um grande estudo e desenvolvimento de técnicas e de soluções logísticas, que foram importantes para a evolução da logística.

As organizações, após a guerra, se utilizaram desses conhecimentos militares para melhorar seus fluxos de suprimentos, produção e distribuição. Segundo Razzolini Filho (2009), depois da guerra o conhecimento adquirido pelos militares para a execução adequada de cada uma dessas tarefas foi transferida para a iniciativa privada e a consequência foi a implementação de uma logística diferenciada que revolucionou o ambiente organizacional nas indústrias, no comércio e nos serviços.

Assim, destaca Razzolini Filho (2009), aconteceu a especialização das organizações, foram desenvolvidas novas experiências para o suprimento nos processos produtivos e foram desenvolvidos, também, novos modos de distribuição dos produtos, atingindo mercados que até então não eram atingidos. As experiências militares com o transporte foram determinantes para o crescimento das operações logísticas nas empresas privadas.

No Brasil, a partir da década de 1970 com o desenvolvimento da indústria automotiva a logística passou a ter grande importância em todas as áreas organizacionais, pois passou a ser um elemento de diferenciação para as organizações, e não mais apenas conceitos de simples movimentação de materiais. Segundo Campos (2007), o histórico da administração moderna permite perceber que uma das etapas da diferenciação passou a acontecer na produção relacionada com velocidade, quantidade e padronização, onde $o$ atendimento ao cliente tornou-se de extrema importância.

A partir dos anos 2000 com a globalização se tornando muito mais presente nas organizações, uma vez que não existiram mais fronteiras para os negócios a logística cresceu de importância. Segundo Razzolini Filho (2007), a globalização trouxe uma nova visão para a logística, pois existe uma lógica clara por trás da atuação das organizações globais: ampliar negócios expandindo mercados, enquanto buscam redução de custos através de economias em compras, produção e distribuição. Para o mesmo autor existem dois grandes desafios nesta era globalizada a serem superados pelas organizações:

a) os mercados são heterogêneos, exigindo uma adaptação rápida e, 
b) não existindo uma coordenação nos processos, a logística torna-se complexa a acaba gerando custos mais elevados.

Assim, com a globalização presente e os mercados cada vez mais competitivos, as organizações têm oportunidades e ameaças e por isso, o desenvolvimento e a evolução da logística tornam-se preponderantes para a sobrevivência empresarial.

\subsection{LOGÍSTICA EMPRESARIAL}

A logística empresarial atua para prover melhor nível de serviços nos canais de distribuição aos clientes e consumidores. Com planejamento, organização e controle, a logística age visando facilitar o fluxo de produtos.

A logística é um assunto vital e econômico para as empresas e seus clientes. A distância entre produtos e clientes é - e sempre será - um empecilho à logística, que busca dispor de bens ou serviços ao consumidor final, na condição física, quando e como quiser. Na visão de Ballou (2007) a logística empresarial trata de todas as atividades de movimentação e armazenagem que facilitam o fluxo de produtos desde o ponto de aquisição da matéria-prima até o ponto de consumo final, assim como dos fluxos de informações que colocam os produtos em movimento, com o propósito de providenciar níveis de serviço adequados aos clientes a um custo razoável.

$$
\text { Para Christopher (2010) a }
$$
logística empresarial vem aumentando sua interação dentro dos processos de gestão das organizações, uma vez que engloba além de estratégias, práticas operacionais que melhoram a competitividade junto o mercado. É um novo paradigma competitivo colocar a empresa num conjunto de competências e capacidades que contemplem todas as áreas da logística especialmente a logística reversa e o cuidado com o meio ambiente.

O mesmo autor destaca que a emergência das organizações que adotam os conceitos de logística empresarial tem tornado as empresas mais eficazes no atendimento das satisfações dos clientes, bem como tem melhorado seus fluxos internos e consequentemente reduzindo custos e desperdícios.

Segundo Novaes (2007) o processo de criação de valor para o cliente faz com que a logística fique posicionada na empresa como uma competência. A logística moderna procura incorporar prazos previamente acertados e cumpridos integralmente, ao longo de toda a cadeia de suprimentos; integração efetiva e sistêmica entre todos os setores da empresa; integração efetiva e estreita (parcerias) com fornecedores e clientes; busca da otimização global, envolvendo a racionalização dos processos e a redução de custos em toda a cadeia de suprimento; satisfação plena do cliente, mantendo nível de serviço preestabelecido e adequado.

A logística empresarial agora já é vista por muitas empresas como fundamental para o sucesso no mercado. Segundo Christopher (2010) observa-se que tradicionalmente para muitas empresas o maior investimento tem sido mais na excelência do produto e menos na excelência do processo. Ressalta o mesmo autor que isso não significa que não se deva enfatizar a inovação do produto, mas é necessário mais ênfase no desenvolvimento e na gestão de processos, visando custos menores, valor agregado aos clientes e mais recentemente cuidado com o meio ambiente. É fundamental que as empresas busquem a excelência tanto nos produtos como nos processos, pois desta forma os clientes certamente reconhecerão a empresa como organização que busca o equilíbrio entre a parte econômica e ambiental.

$\mathrm{Na}$ figura 1 está demonstrada a relação entre a excelência do produto e a excelência do processo. 


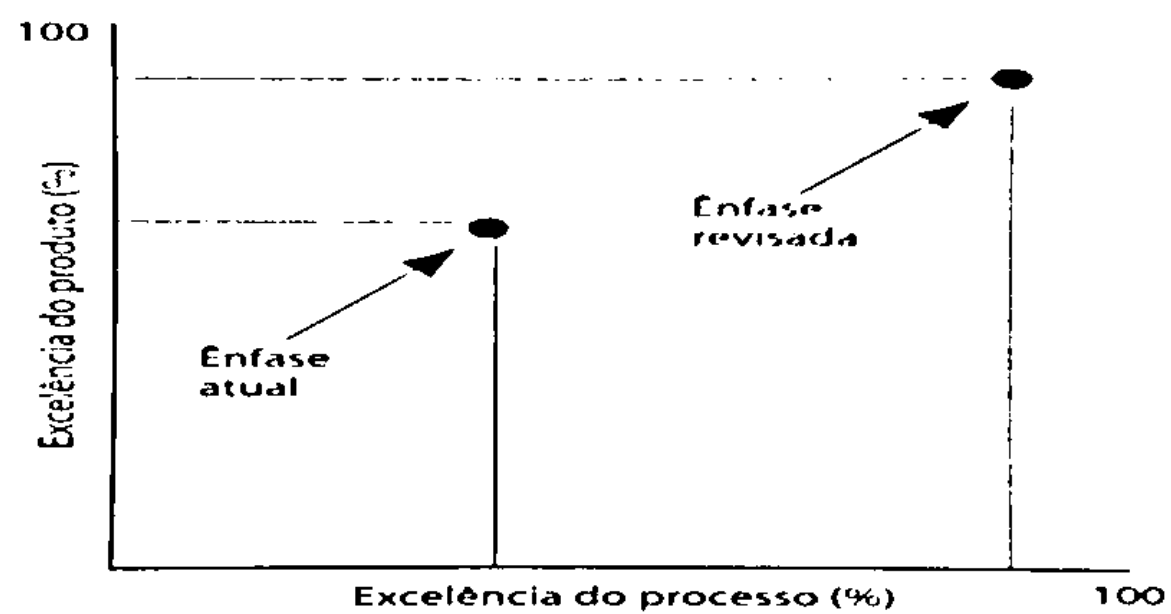

Figura 1: Excelência do produto x excelência do processo

Fonte: Christopher, 2010

A figura 1 mostra, segundo Christopher (2010) a base para competir nesta nova era, ou seja: vantagem competitiva $=$ excelência do produto $\mathrm{x}$ excelência do processo. Fica claro que a ênfase atual precisa evoluir para uma ênfase revisada, melhorando a competitividade.

\subsection{IMPORTÂNCIA DA LOGÍSTICA REVERSA}

Para Leite (2009), a logística reversa é um campo que cresce a cada dia, motivado pela onda de conscientização ambiental e pelas oportunidades empresarias por ela suscitadas.

No Brasil, a logística reversa teve grande relevância no início da década de 1980, mas somente na década de 1990 se tornou mais evidente quando houve uma considerável redução das tarifas de importação em diversos setores econômicos, proporcionalizando maior internacionalização do país. Mas foi no ano de 1994 com a estabilização da moeda que se observou o verdadeiro boom logístico no país, com expressivo desenvolvimento e aumento de transações empresariais em diversas cadeias industriais e agropecuárias.

Segundo Leite (2009) a logística reversa é uma questão bastante ampla visto que ela trata de todos os materiais ou produtos que compreendem retorno ou reuso, além de reciclagem de materiais, que denota grande importância para o meio ambiente. Assim, a logística reversa pode ser definida como a área da logística que trata dos aspectos de retornos de produtos, embalagens ou materiais ao seu centro produtivo. É muito útil nos dias de hoje, pois a preocupação com custos e com o meio ambiente tem aumentado nas organizações. Praticando a logística reversa em seus processos produtivos as organizações podem evitar consequências ambientais e ganhar um diferencial no mercado, pois ainda são poucas que usam essa estratégia.

A legislação ambiental tem encorajado várias empresas a decidir pela implantação de práticas da logística reversa. Como ilustração a Comissão Europeia (European Commission) estabeleceu um conjunto de regras para se fazer $o$ gerenciamento adequado de embalagens (González-Torre et al., 2004). Para os mesmos autores o aumento da reutilização e reciclagem traz vantagens competitivas às empresas.

$\mathrm{Na}$ logística tradicional o processo do fluxo de materiais é a saída dos produtos das empresas com a chegada para o cliente. $O$ processo na logística reversa é invertido, pois é a área da logística que trata do retorno dos produtos, embalagens ou materiais ao seu centro de origem. Nesse contexto, conforme demonstrado na figura 2 , a logística reversa envolve todas as operações relacionadas com a reutilização dos produtos, envolve todos os processos logísticos de coletar, triar, recuperar e ou descartar materiais, peças ou produtos. 
Figura 2: Canais reversos de revalorização.

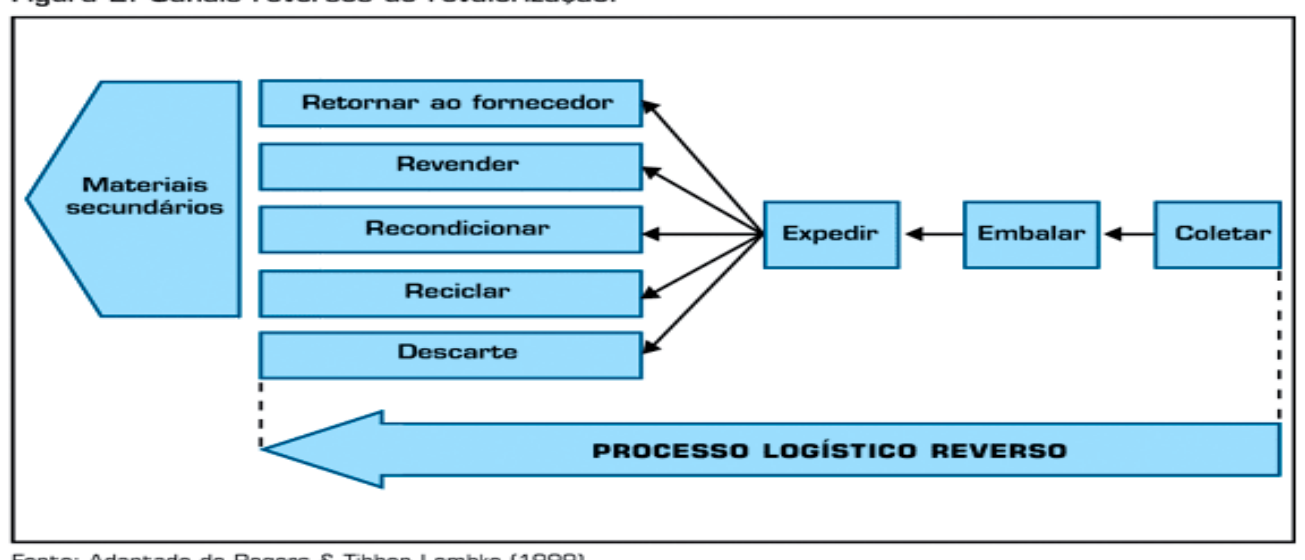

Figura 2: Canais reversos de revalorização

Fonte: Lacerda, 2002.

A figura 2 mostra a representação esquemática dos processos logísticos reversos, conforme a conceituação apresentada anteriormente. Podemos dizer que são várias as causas que levaram as empresas a investirem na logística reversa, pois é um processo comum para a maioria dos negócios. As empresas têm demonstrado crescente interesse tanto sob o ponto de vista de operações como do ponto de vista financeiro. Nesse sentido a logística reversa se alinha com a estratégia das organizações.

Outra questão importante referese à responsabilidade dos fabricantes pela destinação dada a seus produtos após sua entrega ao cliente e o respectivo consumo. Muitos desses produtos são incinerados ou descartados com danos significativos ao meio ambiente. Mudanças na legislação, no perfil do consumidor, pressão por redução de custos tem feito com que as empresas se preocupem com o destino correto de seus produtos no que se refere a descarte. (BOWERSOX \& CLOSS, 2001).

\subsection{EQUIPAMENTOS DE MOVIMENTAÇÃO DE PRODUTOS}

Conforme as dimensões e os tipos de carga a serem movimentadas, utilizam-se diferentes tipos de equipamentos e acessórios para movê-las. Para esse fim, existem empilhadeiras elétricas, a combustão e paleteiras elétricas e manuais (DIAS, 2005).
O Equipamento de Movimentação de Materiais (MHE) é usado para carregar, descarregar e movimentar produtos dentro das áreas do depósito. $\mathrm{O}$ tipo de MHE selecionado dependerá dos tipos de armazenamento e das atividades desempenhadas na Unidade.

\subsubsection{TIPOS DE EQUIPAMENTOS DE MOVIMENTAÇÃO}

Existem vários tipos de equipamentos de movimentação. $\mathrm{Na}$ empresa pesquisada os principais equipamentos estão descritos a seguir.

\subsubsection{PALETE}

Conforme Chiavenato (2005), o palete é um estrado de madeira que possui dimensões e medidas padronizadas, dependendo das necessidades dos produtos e do espaço físico que se tem. É um equipamento auxiliar de armazenagem e movimentação, concebido para permitir o manuseio de materiais por meio de veículos automotores, chamados empilhadeiras e transpaleteiras. Trata-se de um equipamento essencial para as operações internas dos depósitos e centros de distribuição, bem como para o atendimento aos clientes.

$\mathrm{Na}$ organização estudada, são utilizados paletes PBR, os quais possuem as seguintes características:

- Quatro entradas

- Comprimento: $1200(+0$-5) $\mathrm{mm}$

- Largura: $1000(+0$-5) $\mathrm{mm}$ 
- Altura

- Total: $146(+2-4) \mathrm{mm}$

- Livre: 100 (+0 -4) mm

- Material: Chapas de Eucalipto e Pinus-Elliotti aparelhada numa face, com tratamento contra insetos e mofo.

- Peso unitário: 40 kg (+/- 1,5 kg)
Este equipamento permite a movimentação por empilhadeira e transpaleteira pelos quatro lados - face simples.

A figura 3 demonstra o modelo principal de palete utilizado pela empresa pesquisada.

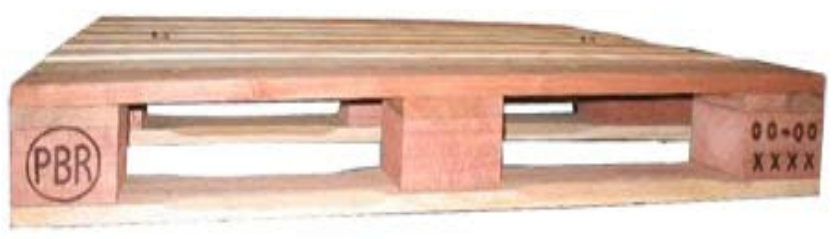

Figura 3: Palete utilizado na empresa pesquisada

Fonte: Foto fornecida pela empresa

As tábuas e blocos do palete devem ter duas bordas esquadrejadas. Não são permitidos topos com rebarbas ou outros defeitos de processamento que possam reduzir a resistência mecânica ou mesmo provocar acidentes.

As quinas dos paletes devem ser cortadas a $45^{\circ}$, com as arestas de $10 \mathrm{~mm}$ de comprimento.

\subsubsection{2 MODELOS CONTRABALANÇADA E RETRAK}

Existem vários modelos de empilhadeiras, à combustão e elétricas, as quais devem ser utilizadas conforme o ambiente possibilita. Em ambientes fechados e alguns lugares onde não é permitido o uso deste equipamento à combustão, faz-se necessário o uso da empilhadeira elétrica. (DIAS, 2005).

As

empilhadeiras contrabalançadas são utilizadas para carga, descarga e armazenamento no tipo de empilhamento "blocado/livre", em depósitos que possuem corredores largos e/ou para operações externas (piso acidentado e superfície irregular). Estas podem ser movidas a eletricidade, diesel ou gás. Em armazéns de alimentos, como no caso da empresa estudada, é recomendado o tipo elétrico. A altura padrão de elevação é de 6 metros, mas é possível encontrar equipamentos especiais para aplicações mais altas (até $6,7 \mathrm{~m})$.

$\mathrm{Na}$ figura 4 aparece um modelo de empilhadeira contrabalançada.

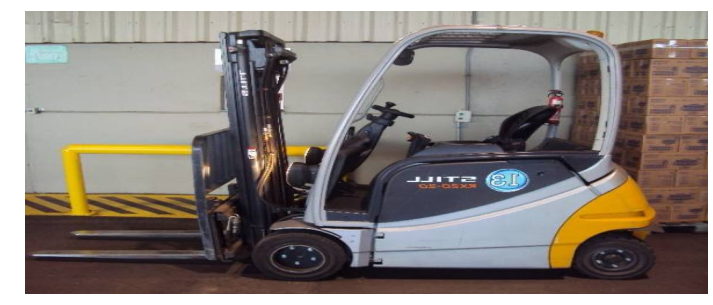

Figura 4: Empilhadeira contrabalançada

Fonte: Foto fornecida pela empresa

Este modelo de empilhadeira mostrado na figura 4 é um dos modelos que a empresa usa nas suas atividades de movimentações internas.

O outro modelo de empilhadeira é chamado Retrak e é utilizada para movimentar cargas em depósitos que possuem corredores estreitos e racks com alturas elevadas (até 10 metros). Este é o equipamento padrão em armazéns equipados com racks seletivos. Só é adequado para operações internas. $\mathrm{O}$ uso 
desse equipamento não é ideal para operações em docas.

\subsubsection{3 \\ TRANSPALETEIRA \\ MANUAL}

As transpaleteiras hidráulicas são possuem garfos de metal que foram exatamente fabricados para encaixar-se nos paletes, permitindo o seu transporte. (DIAS, 2005).

A figura 5 mostra a transpaleteira hidráulica utilizada pela empresa em seus processos de movimentações de cargas internos.

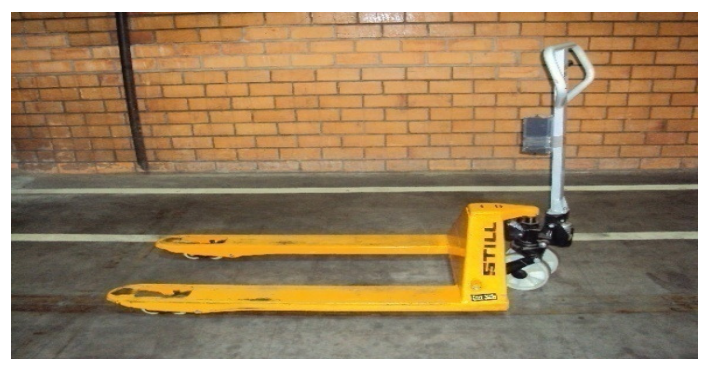

Figura 5: Trasnpaleteira manual ou hidráulica.

Fonte: Foto fornecida pela empresa

Este equipamento mostrado na figura 5 é usado para movimentar horizontalmente e manualmente cargas com paletes, sendo a sua finalidade movimentar cargas em distâncias curtas e pisos horizontais planos, em pequenos depósitos com atividades limitadas.

\subsection{GESTÃO DE CUSTOS}

A gestão de custos ganhou nos últimos anos uma atenção especial das empresas, uma vez que se faz necessário ter um acompanhamento cada vez mais adequado visando buscar alguma vantagem competitiva. As empresas evoluíram de tal forma que as informações sobre os custos sejam de produção, distribuição ou armazenamento, se tornaram importante instrumento gerencial, surgindo assim o controle dos custos, que permitiu aos dirigentes saber quanto custa cada etapa, cada processo de sua organização.

Segundo Wernke (2004) para uma eficiente gestão de custos é necessária a compreensão dos conceitos básicos relacionados ao tema. Várias interpretações podem conduzir a diferentes entendimentos do que se pode classificar como gastos, investimentos, despesas, perdas, desperdícios e custos. Por isso objetivando utilizar as informações de custos para fins gerenciais, o referido autor adota conceitos básicos associados a suas características conforme mostrado na figura 6 .

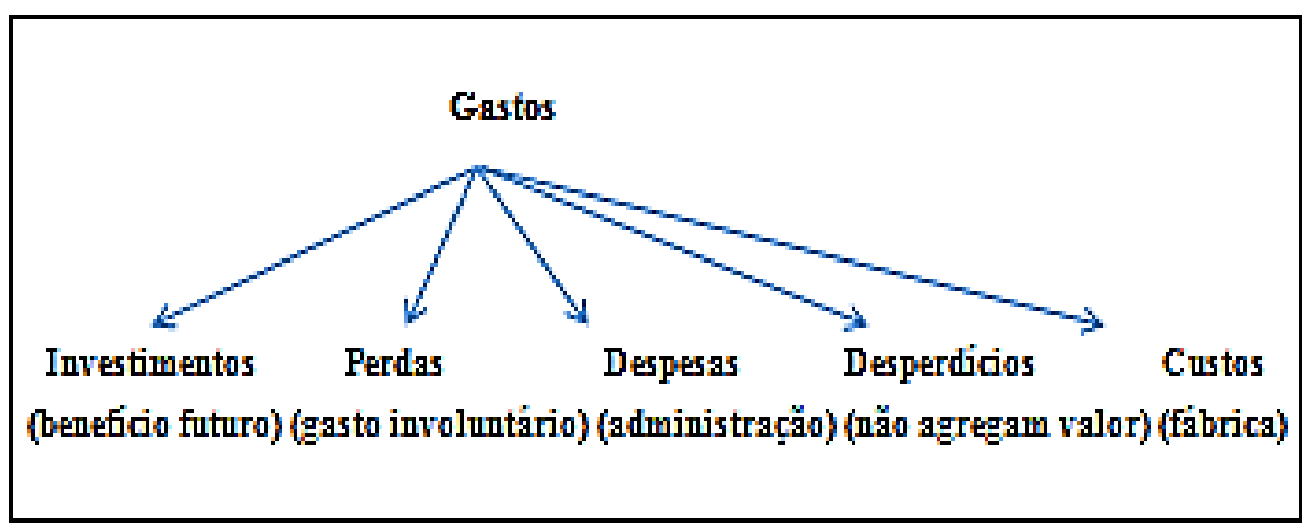

Figura 6: Definições básicas sobre gastos.

Fonte: Wernke, 2004 - adaptada pelos autores.

Dentre os conceitos básicos utilizados por Wernke (2004), conforme aparece na figura 6 , o desperdício pode englobar custos e despesas utilizadas de 
forma não eficiente. Ou seja, são considerados desperdícios todas as atividades que não agregam valor e que resultam em gastos de tempo, dinheiro, além de adicionarem custos desnecessários aos produtos. Para manterem-se competitivas as empresas, entre outras estratégias, estão procurando a eliminação de desperdícios em todas as fases produtivas ou administrativas, por isso $\mathrm{o}$ correto entendimento dos componentes da gestão de custos é imprescindível para que os gestores consigam melhores resultados em relação aos concorrentes.

Para obter melhor desempenho, um negócio ou empresa precisa desenvolver e sustentar uma vantagem competitiva, assim ressalta Wernke (2004), levantar quais são os fatores que efetivamente provocam os custos, por meio de uma relação de causa-efeito que reflita de forma mais precisa a realidade, pois o custo é causado por muitos fatores que se interagem de forma complexa.

Chiavenato (2005) enfatiza que o dinheiro constitui um dos recursos mais escassos e caros do nosso mundo. É difícil ganhá-lo e fácil perdê-lo, tanto na atividade pessoal como na atividade empresarial, por isso cada empresa precisa saber lidar com seus recursos internos e obter o máximo de rendimento conhecendo as necessidades da empresa e evitando os desperdícios com gastos e custos desnecessários. Nenhuma empresa pode se dar ao luxo de não ter controle sobre seus custos, sob o risco de sucumbir diante do competitivo mercado.

Desta forma, otimizar a utilização de equipamentos internos com uma administração eficiente e eficaz dos custos torna-se um objetivo a ser perseguido pelos gestores na busca de redução de custos que refletirão na competitividade da empresa.

\subsection{ADMINISTRAÇÃO DA RECUPERAÇÃO DE PRODUTOS}

Para Razzolini Filho (2009) uma área de estudos que tem ocupado espaço no ambiente empresarial é a chamada administração da recuperação de produtos, que pode ser definida como a gestão de todos os produtos, seus componentes e todos os materiais usados e descartados nos processos produtivos das empresas.

No quadro 1 estão descritas as opções de recuperações de equipamentos ou produtos.

Quadro 1: Resumo de operações de recuperação de produtos

\begin{tabular}{|l|l|l|}
\hline $\begin{array}{c}\text { Opções de } \\
\text { Recuperação }\end{array}$ & Nível de desmontagem & \multicolumn{1}{|c|}{ Resultados } \\
\hline Reparo & Produto & Algumas partes reparadas ou substituídas. \\
\hline Renovação & Módulo & Alguns módulos reparados ou substituídos. \\
\hline Remanufatura & Parte & Partes usadas em novos produtos. \\
\hline Canibalização & $\begin{array}{l}\text { Recuperação seletiva de } \\
\text { partes }\end{array}$ & $\begin{array}{l}\text { Algumas partes reutilizadas e outras } \\
\text { descartadas. }\end{array}$ \\
\hline Reciclagem & Material & Materiais utilizados em novos produtos. \\
\hline
\end{tabular}

Fonte: Razzolini Filho, 2009 - adaptado pelos autores.

A administração de recuperação de produtos é uma importante área da gestão na qual se insere a logística reversa, com resultados importantes conforme demonstrados no quadro 1. Razzolini Filho (2009) destaca que além de ser uma ferramenta importante, a administração de recuperação de produtos possibilita alguns ganhos significativos no gerenciamento da cadeia logística. O aumento de rentabilidade pela recuperação de valor econômico e ganhos de imagem, pela recuperação de valor ecológico são dois ganhos que se destacam e estão em conformidade com o presente trabalho.

\section{RESULTADOS}

Foi observado pelos pesquisadores que o palete PBR-l é considerado um ativo da empresa e por isso sua relevância neste contexto. A unidade deve gerenciar o parque de equipamentos sob suas responsabilidades 
de forma eficiente, buscando otimizar o fluxo dentro da cadeia e evitar estoque excedente.

Houve constatação de que a manutenção da quantidade, qualidade e apresentação dos equipamentos em estoque deve ser motivo de cuidado constante por parte do responsável pela unidade, que deve zelar pela sua integridade, bem como monitorar o alinhamento entre o estoque físico $\mathrm{e}$ contábil.

\subsection{RECEPÇÃO DE PALETES}

Tendo em vista que a logística reversa se dá quando há um retorno de um produto ou material ao seu ponto de origem, neste caso o palete, pode ser observado no gráfico 01, mês a mês a entrada de paletes que retornam ao depósito.

São diversos tipos de acordos firmados entre empresa $x$ cliente. Há clientes que devolvem o palete no ato da descarga, para casos onde isso não é possível o cliente emite um vale palete, que é um documento em papel timbrado emitido pelo cliente para devolução posterior dos equipamentos à companhia. Devem constar neste documento as seguintes informações:

número da nota fiscal emitida pela empresa, quantidade de equipamentos, data da recepção, nome e assinatura do responsável pela emissão do documento. Esses vales palete retornam à empresa pela transportadora, que de posse desses documentos encaminha ao setor responsável pelo controle dos paletes, após analisar todos os vales, repassa ao setor de transportes para programar as coletas nos clientes.

No gráfico 1 está demonstrada a relação quantidade $\mathrm{x}$ valor no processo de entrada de paletes.

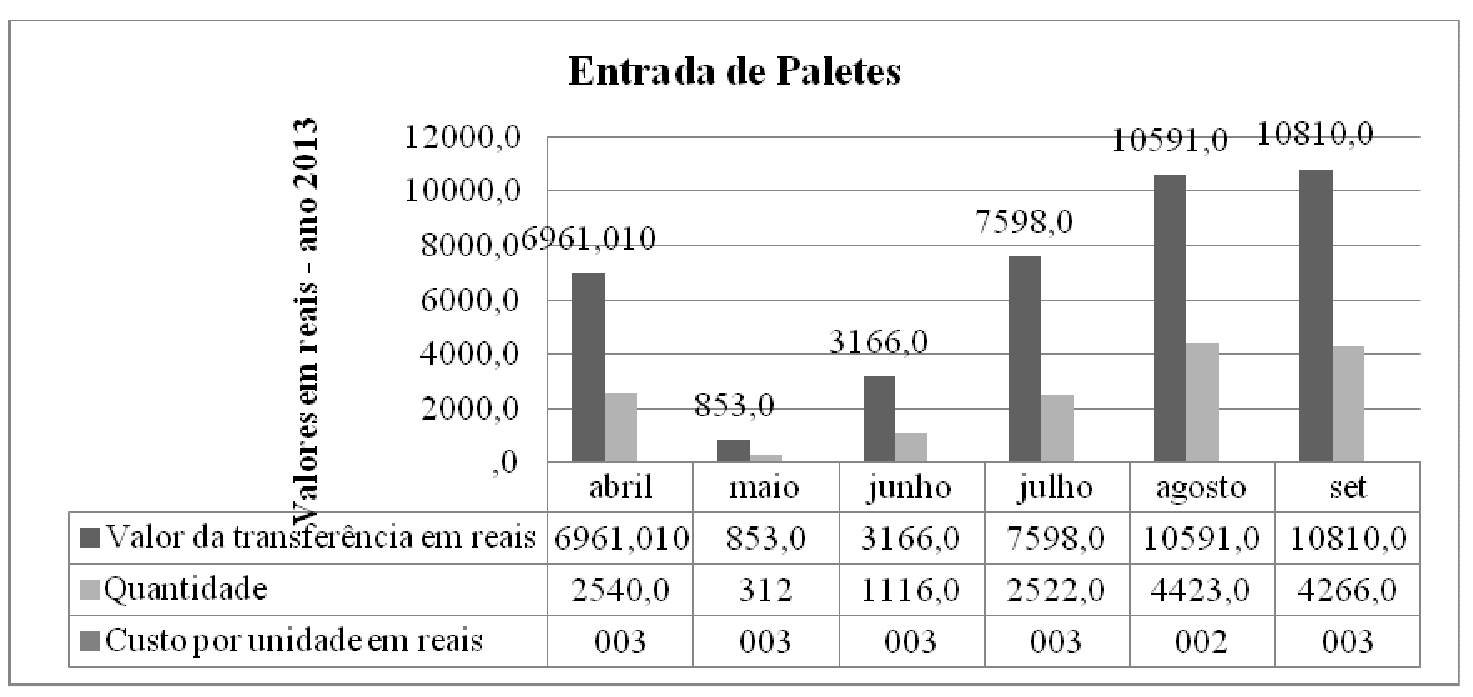

Gáfico 1: Entrada de paletes.

Fonte: Dados coletados na pesquisa

O gráfico 1 corresponde ao total de paletes que deram entrada no depósito, ou seja, paletes que retornaram de clientes, transportadoras ou outras unidades da empresa. Analisando este gráfico nota-se o custo com valor de transferências para retorno dos paletes, este custo refere-se ao frete pago nas coletas efetuadas no período, o qual chegou a mais de dez mil reais nos meses de agosto e setembro de 2013, contrapondo-se ao mês de maio, onde houve a coleta de apenas 312 unidades, o que gerou um gasto de $\mathrm{R} \$ 853,00$ (oitocentos e cinquenta e três reais). Essa diferença de unidades coletadas por mês pode ocorrer devido à empresa estar com o estoque abastecido, ou seja, as coletas são efetuadas dependendo da necessidade, tanto dos distribuidores, clientes ou transportadoras em conjunto com a empresa, caso não haja a necessidade desta última na recepção dos paletes, estes podem ser direcionados para outras unidades. Em acompanhamento ao transporte de paletes no período de pesquisa foi possível 
observar que, em muitas cargas a quantidade transportada varia de acordo com a necessidade e que isto não impacta de forma relevante no custo do transporte, tendo em vista que o cálculo é realizado de seguinte forma:

Tarifa $=80 \%$ do frete origem dividido pela capacidade do veículo multiplicado pela quantidade transportada.

Considera-se apenas $80 \%$ pois este processo de logística reversa só é realizado quando oriundo de um abastecimento de produtos, ao cliente ou distribuidor onde a coleta deve ser realizada.

\subsection{TRIAGEM DOS PALETES}

Todos os paletes que retornam para a empresa passam por uma triagem, pois muitos deles voltam danificados, fora do padrão da empresa ou são descartáveis. Os equipamentos que apresentam defeitos devem ser encaminhados para conserto, ou descartados e ajustados no sistema. A triagem citada anteriormente também é feita por uma empresa terceirizada, gerando assim mais um custo para a empresa. Pode-se perceber que a empresa adota uma política de só efetuar o descarte do palete quando este não apresenta mais condições de uso e nem conserto. Este procedimento tem um custo de $\mathrm{R} \$ 0,45$ (quarenta e cinco centavos) por palete. A triagem acontece no pátio da empresa, onde há uma área destinada à descarga de paletes e também triagem. Toda a descarga de paletes que retornaram é identificada, para um melhor controle.

Um dado importante observado é a questão segurança, pois a empresa adota a política de segurança em primeiro lugar, por isso em todas as suas operações, visa a segurança do seu colaborador. Todavia não seria diferente na hora de efetuar a triagem dos paletes, pois são fornecidos todos os equipamentos de proteção individual (EPI) necessários para a realização das tarefas. Os EPI's são: luvas, botinas de segurança e óculos de proteção.

Sob a perspectiva da logística como gerenciamento de processos a triagem constitui-se numa importante etapa na reciclagem ou na substituição de materiais para realimentar o processo ao qual àquele ou àqueles materiais pertencem.

O gráfico 2 demostra a triagem de paletes com os valores correspondentes.

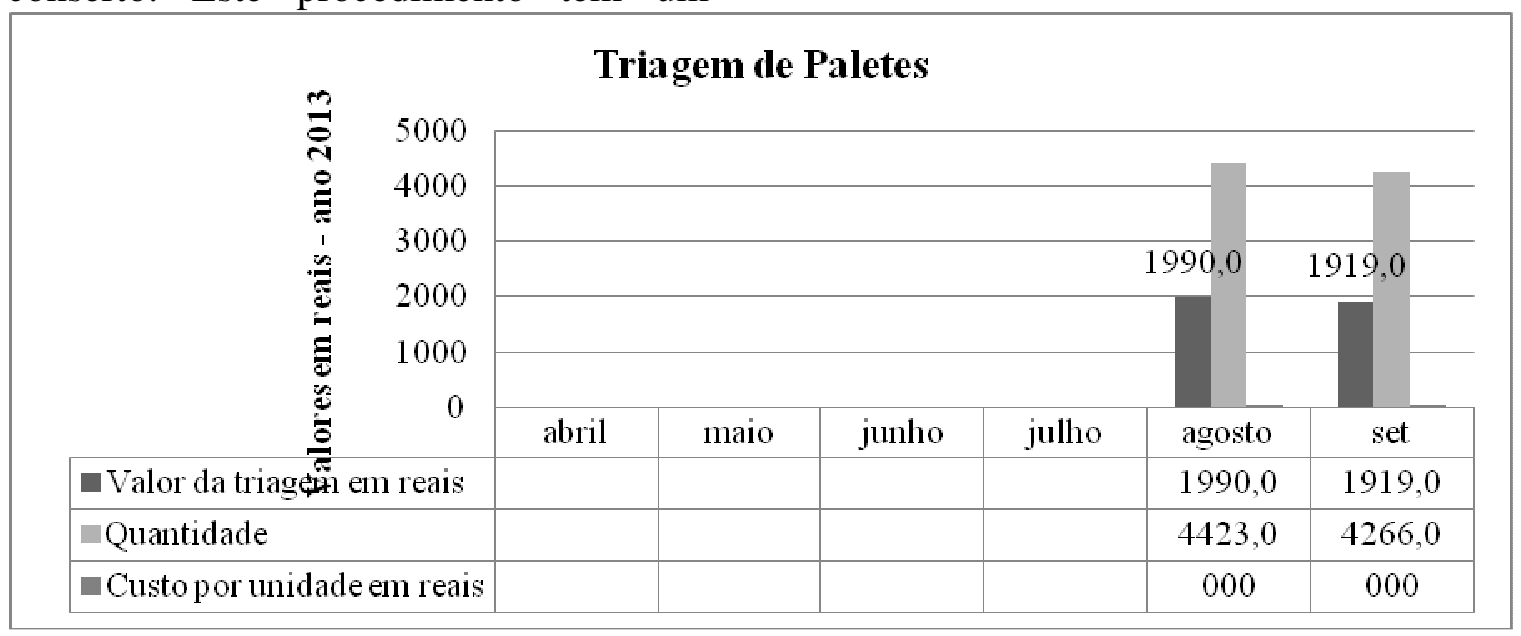

Gráfico 2: Triagem de paletes.

Fonte: Dados coletados na pesquisa.

As informações do gráfico 2 correspondem ao resultado obtido através da quantidade de paletes triados. Conforme dados levantados na pesquisa, o preço acertado é calculado em cima do tempo disposto para executar a função, e também o lucro para a empresa contratada. Como pode ser visto, a organização iniciou este processo de triagem no mês de agosto de 2013 com o qual a empresa teve um custo em torno de $\mathrm{R} \$ 2.000,00$ (dois mil reais), gasto esse 
observado para a triagem que é $\mathrm{R} \$$ 0,45(quarenta e cinco centavos), por unidade de palete triada. Para este processo a empresa terceirizada dispôs de dois funcionários. Como pode ser visto no gráfico, nos meses anteriores não existem valores nem quantidades apontadas, pois este processo era realizado pelos colaboradores da companhia.

\subsection{CONSERTO DE PALETES}

Analisando o gráfico 3, que se refere ao total de paletes quebrados, podemos observar em unidades e valores, mês a mês, o total de paletes danificados e o valor (custo) do conserto desses paletes. Como um dos objetivos deste trabalho é levantar os custos que a empresa tem com os processos reversos de paletes, foi apurado na pesquisa que para cada palete consertado a empresa tem um custo de $\mathrm{R} \$ 5,00$ (cinco reais), o que somou no período da pesquisa, valores entre $R \$ 3.000,00$ (três mil reais) e R\$ 9.750,00 (nove mil setecentos e cinquenta reais), pois o custo para $\mathrm{o}$ conserto é de $\mathrm{R} \$ 5,00$ (cinco reais) por unidade. Muitos desses paletes quebrados retornam de clientes ou transportadoras. Quando isto acontece a companhia emite um boletim de ocorrência (BO) para posterior cobrança. Sendo necessário cobrar o conserto, o custo de $\mathrm{R} \$ 5,00$ (cinco reais) é repassado ao cliente ou transportadora. Existem clientes que não são cobrados pelo conserto de paletes, para estes casos o custo é absorvido pela unidade.

Muitos paletes são avariados durante a operação, nas movimentações com empilhadeiras, na utilização para o processo de fabricação e na área de depósito. No que se trata de paletes quebrados por empilhadeiras foi constatado durante a pesquisa que esse fato ocorre quando o operador, ao introduzir a lança de maneira inadequada para elevar a carga, força o palete e faz com que o mesmo seja avariado.

Corroborando com Razzolini Filho (2009) a recuperação de produtos praticada pela empresa se configurou numa importante área de gestão na qual a administração de recuperação de produtos possibilita alguns ganhos significativos no gerenciamento da cadeia logística.

O conserto de paletes com seus valores está demonstrado no gráfico 3 .

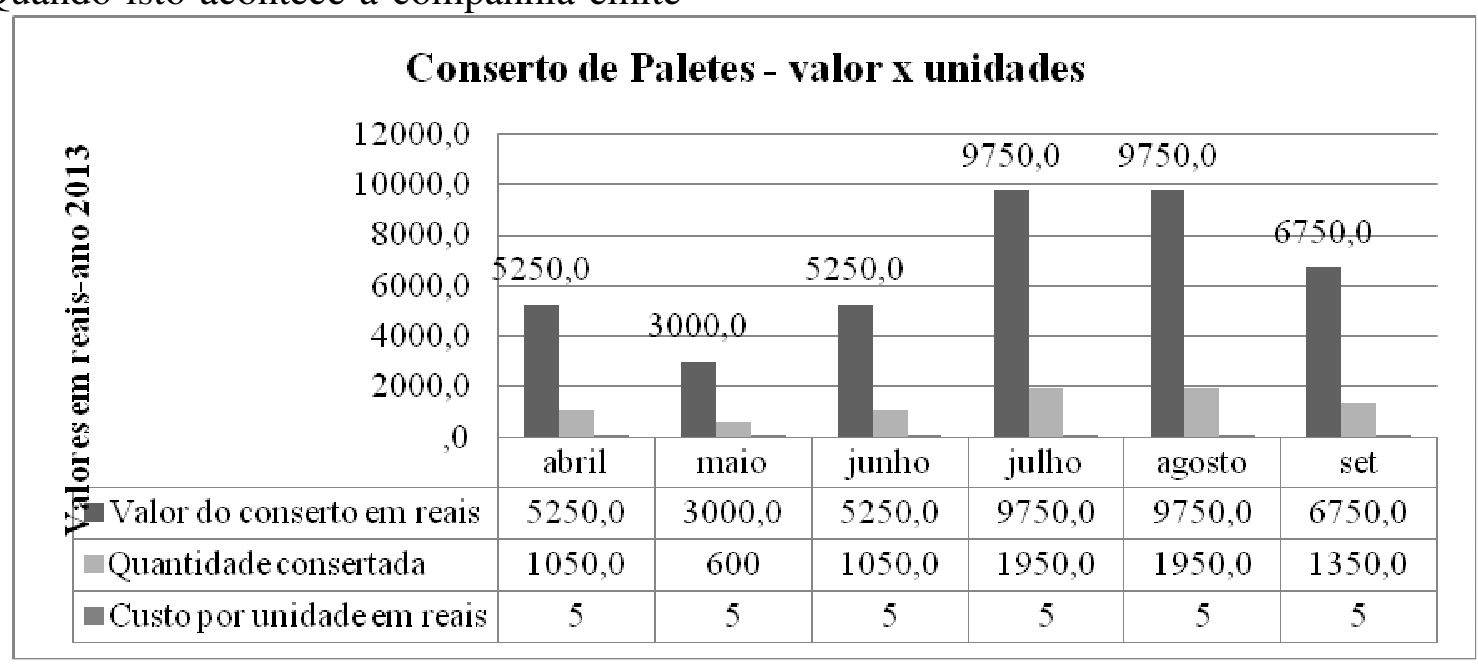

Gráfico 3: Conserto de paletes.

Fonte: Dados coletados na pesquisa.

\subsection{DESCARTE DE PALETES}

Todos os paletes considerados descartáveis ficam alojados separadamente, posteriormente são vendidos como sucata para uso em olarias ou depósitos de secagem de sementes.
Esta é uma ação que contempla as questões ambientais, porque é dado um destino correto aos materiais que não servem mais à empresa.

Razzolini Filho (2009) destaca a importância do descarte adequado de 
materiais e embalagens, pois as pessoas já repensam condutas de como reutilizar ou descartar adequadamente embalagens ou resíduos de pós-consumo exigindo que principalmente as empresas tenham práticas adequadas neste sentido.
O descarte de paletes, mostrado no gráfico 4 é um dos processos que devem ter maior atenção por parte da empresa em virtude dos efeitos do descarte.

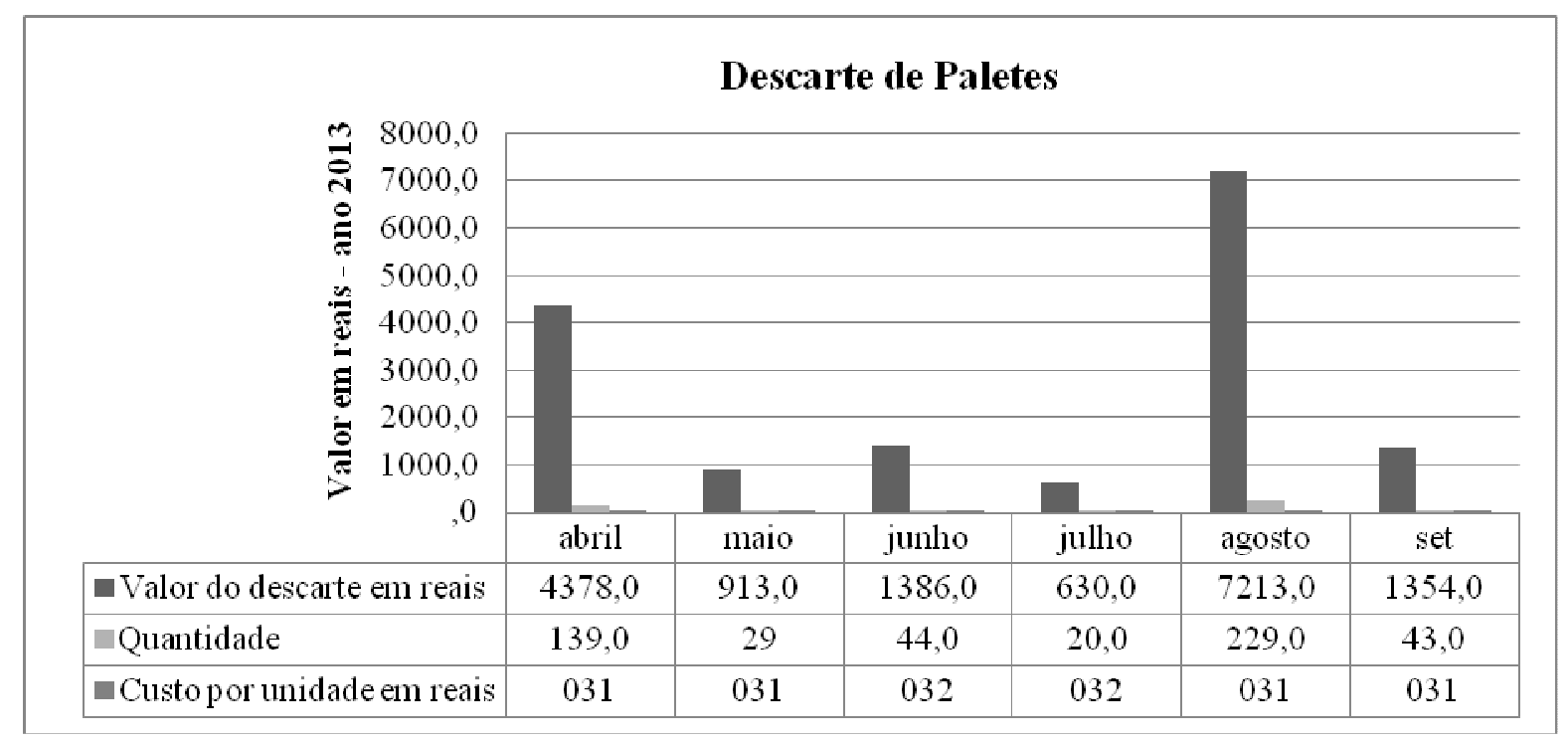

Gráfico 4: Descarte de paletes.

Fonte: Dados coletados na pesquisa.

O gráfico 4 corresponde ao resultado obtido com todos os paletes que são descartados pela empresa. Por trabalhar somente com paletes no padrão brasileiro (PBR), a empresa estudada tem necessidade de descartar os paletes fora de padrão que porventura retornam de clientes, transportadoras e outras unidades. Pode-se notar que quanto mais paletes descartados, maior é o custo no mês, pois cada palete descartado tem um custo R\$ 31,50 (trinta e um reais e cinquenta centavos).

Analisando o gráfico 4 foi possível perceber que a empresa tem em média mais de $\mathrm{R} \$ 2.500,00$ (dois mil e quinhentos reais) de custo com este processo. Foi detectado durante a pesquisa que a maioria dos paletes fora de padrão, que são descartados, são aqueles que retornam de distribuidores da companhia, visto que há um acordo entre empresa e distribuidor para que esses equipamentos ruins não sejam cobrados, sendo este custo absorvido pela empresa. Quando há o retorno por parte de clientes ou transportadoras, a empresa cobra este custo. Em um primeiro momento, os paletes que retornam dos clientes são incorporados ao estoque e depois de identificados na triagem como fora dos padrões da companhia tem que ser removidos do sistema, pois para a empresa o palete é considerado um ativo como qualquer outra mercadoria, e estando no estoque ele é considerado um ativo "vivo", mas na verdade não poderá ser utilizado.

\section{SUGESTÕES}

Em função das observações e a análise dos dados da pesquisa, os pesquisadores formularam algumas propostas para melhoria da logística reversa na empresa.

Cabe aqui ressaltar que embora o presente estudo de caso tenha sido elaborado em uma única empresa, acredita-se que o mesmo, embora com esta limitação, possa servir de base para outros estudos em outras empresas uma vez que este equipamento (palete) é muito utilizado em organizações que trabalham com estoque e movimentações de mercadorias. Por isso, acredita-se que este artigo possa contribuir com a 
utilização da logística reversa deste tipo de equipamento.

- Uma questão relevante é a triagem, como mostrado anteriormente, que é feita por uma empresa terceirizada, gerando um custo considerável para a companhia conforme demonstrado no gráfico 2. Propõe-se que a empresa efetue a contratação de dois operadores para efetuar essa função haja vista que tendo dois funcionários para desempenhar a triagem a empresa tem maior controle sobre o processo.

- $\quad$ Para uma redução dos custos com paletes quebrados na operação, custos estes demonstrados no gráfico 3, os paletes ficam em pilhas de dez, fazendo com que o operário tenha que baixá-los manualmente. Em muitos casos há uma queda, ocasionando danos, não somente aos equipamentos, mas também aos envolvidos neste processo. Uma sugestão seria a criação de um equipamento com um sensor de movimento, equipamento este para manipulação de paletes. Um equipamento de sistema mecânico, ou dispensador de paletes para facilitar o manuseio destes, evitando quebras, acidentes com os colaboradores, bem como favorecendo a ergonomia, otimizando tempo e custos que também é importante para a empresa.

- $\quad$ Observou-se que em muitos casos, os paletes que retornam quebrados de alguns clientes têm os custos absorvidos pela empresa, por estes clientes fazerem parte de uma carteira mais rentável para a organização. Em muitos clientes a devolução é no ato da entrega do produto, porém são devolvidos os paletes que estão no estoque do comprador, sendo que a transportadora responsável pela entrega retorna com os paletes para o depósito. Quando isto acontece e há evidência de paletes quebrados, a empresa não repassa o valor do conserto para nenhuma das partes. A proposta seria repassar o custo de conserto e descarte destes paletes para os clientes, já que os mesmos saíram em boas condições de uso.
- $\quad$ Outra questão importante é a dos paletes que retornam fora do padrão PBR, para os quais apenas os que retornam do transportador é feito o boletim de cobrança. Em contrapartida, todos os paletes fora de padrão que retornam dos distribuidores não são cobrados, ou seja, todo o custo com o descarte destes equipamentos é da empresa. Conforme é possível visualizar na análise do gráfico 4 , o custo com o descarte destes paletes é elevado, desta maneira, sugere-se que estes valores sejam repassados aos distribuidores. Devido à parceria entre empresa e distribuidor relatada anteriormente, sugere-se que inicialmente os custos de descarte sejam repassados gradativamente ao distribuidor, até $\mathrm{o}$ alcance dos cem por cento dos custos desta operação para o mesmo.

Nesta linha de pensamento considera-se de acordo com o esperado pelo estudo, os seguintes prazos para implementação desta recomendação;

A partir da data de divulgação da circular por parte da empresa e ciência dos distribuidores deste novo procedimento, considera-se 30 dias para o início do projeto, utilizando a seguinte sistemática de cobrança e rateio no descarte dos paletes:

a) da data de início a 90 dias do projeto, a empresa absorverá $70 \%$ dos custos de descarte;

b) de 91 dias a 180 dias, a empresa arcará com $50 \%$ dos custos;

c) de 181 dias até 210 dias, a empresa arcará com $25 \%$ dos custos;

d) a partir de 211 dias, o custo de descarte fica todo por conta do distribuidor.

Por fim, sugerem-se novos estudos para medir os custos após as implementações sugeridas uma vez que acredita-se que os resultados com base no estudo desenvolvido, neste processo de logística reversa serão significativos.

\section{CONSIDERAÇÕES FINAIS}

A sustentabilidade representa a busca de um novo padrão de desenvolvimento com crescimento econômico preservando recursos naturais. Porém uma amplitude maior do conceito de sustentabilidade que avança além da 
preservação de recursos naturais para conservação do meio ambiente, redução de custos com energia, reutilização de materiais, investimento em pesquisa e desenvolvimento, geração de empregos, entre outros, fazem parte de uma nova visão entre empresários e empresas. Adotar práticas de gestão sustentável passou a ser visto pelas empresas como um negócio.

Uma empresa para torna-se sustentável deve ir além do produzir e vender. $\mathrm{O}$ uso das práticas da logística reversa reduz custos e melhora o gerenciamento da sua cadeia produtiva criando maior conscientização da importância da sustentabilidade e da adoção de suas práticas $\mathrm{n}$ dia-a-dia das empresas.

Através da pesquisa realizada foi possível verificar quais são os custos que a empresa tem com a sua logística reversa e a sua importância. Ficou constatado com o processo reverso dos paletes, que a companhia tem um custo elevado, conforme demonstrado nos gráficos apresentados. A empresa pesquisada dá muita importância à questão da origem da matéria prima do seu fornecedor de consertos, garantindo assim que a lei seja observada em relação à utilização de recursos oriundos de reflorestamento, assegurando a observância da preservação de recursos ambientais, ou seja, utilizando materiais com certificação de órgãos ambientais.

Ao final deste trabalho pode-se verificar a importância da logística e da logística reversa na empresa. Logística esta que a cada dia se demonstra mais importante para todo tipo de empresa. Não seria diferente na empresa estudada, pois a logística reversa é fundamental para o processo de retorno dos paletes para a companhia. Fica visível para a empresa que seus custos com a reversa de paletes é alto, indo de encontro com o que as companhias querem, que é, minimizar seus custos para melhorar sua rentabilidade e competitividade. Motivada pela redução dos custos reversos e logísticos a empresa tende a desenvolver um processo mais rentável e vantajoso para suas operações, visto que a ideia principal desta pesquisa foi de levantar os custos que a empresa tem com todo o processo reverso de paletes.

Embora este estudo traga contribuições com a temática estudada é importante o surgimento de novas pesquisas sobre a logística reversa, analisando o retorno desses materiais, pois sua reutilização pode evitar emissões de gazes poluentes reduzindo e efeito estufa. Um balanceamento entre a reutilização e o simples descarte é um tema a ser pesquisado.

Estão ocorrendo mudanças no ambiente empresarial, visto que cada vez mais há o retorno de bens, produtos e materiais que possam ser reaproveitados contribuindo dessa forma com a diminuição de extração de matériasprimas da natureza. Ao encontro disto é oportuno falar da crescente importância da logística reversa não só na empresa estudada que faz a reversa de paletes, mas sim em todas as áreas onde é necessário retorno de algum tipo de produto ou material, pois em muitas empresas a logística reversa constitui parte integrante das estratégias empresariais.

Esse processo que podemos chamar de remanufatura busca minimizar os impactos no meio ambiente por meio da reutilização de materiais e que segundo Flappper e Teunter (2004) reduz o uso de energia e também o uso de aterros para resíduos, contribuindo desta forma para o avanço da logística reversa.

Assim,finalizando consideramos que os resultados aqui demonstrados podem contribuir com as questões básicas, porém fundamentais, da logística reversa, uma vez que é possível com práticas simples e objetivas diminuir os impactos ambientais que determinados materiais de uso contínuo nas empresas provocam. Desta forma, considera-se atingidos os objetivos propostos uma vez que foi possível identificar os custos com o processo e ao mesmo tempo sugerir melhorias. 


\section{REFERÊNCIAS}

BALLOU, R. H. 2007. Logística empresarial. São Paulo, Atlas.

BOWERSOX, D. J., CLOSS, D. J. 2001. Logística Empresarial. O processo de integração da cadeia de suprimento. São Paulo: Atlas.

CAMPOS, L.F. R.; BRASIL, C. V. M. 2007. Logística: teia de relações. Curitiba: Ibpex.

CHIAVENATO, I. 2005. Administração de materiais: uma abordagem introdutória. 3 reimpr. Rio de Janeiro : Elsevier.

CHIAVENATO, I. 2005. Administração financeira: uma abordagem introdutória. 5 reimpr. Rio de Janeiro: Elsevier.

CHRISTOPHER, M. 2010. Logística e gerenciamento da cadeia de suprimentos: criando redes que agregam valor. 2. ed. São Paulo : Cengage Learning.

CRUZ, J. A. W. 2011. Gestão de custos: perspectivas e funcionalidades. Curitiba: Ibpex.

DIAS, M. A. P. 2005. Administração de materiais: princípios, conceitos e gestão. 5. ed. São Paulo: Atlas.

FLAPPER, S. D. P.; TEUNTER, R. H. 2004. Logistic planning of rework with deteriorating
International Journal of Production Economics. v.88,p.51-59.

GONZÁLEZ-TORRE,P.L.;ADENSO-

DIAZ,B;ARTIBA,H.2004.Environmental and reverse logistics policies in European bouling and packing firms. International Journal of Production Economics, v.88, n. 1,p.95-104..

LACERDA, 1. 2002 Logística reversa: uma visão sobre os conceitos básicos e as práticas operacionais. Revista Tecnologística, São Paulo, v. 6, n. 74, p. 46-50.

LEITE, P. R.. 2009. Logística reversa: meio ambiente e competitividade. 2. ed. São Paulo. Pearson Prentice Hall.

NOVAES, A. G. 2007. Logística e gerenciamento da cadeia de produção. 3 . ed. Rio de Janeiro: Elsevier.

RAZZOLINI FILHO, E.; BERTÉ, R. 2009. O reverso da logística e as questões ambientais no Brasil. Curitiba: Ibpex,

RAZZOLINI FILHO, E. 2007. Logística empresarial no Brasil: tópicos especiais. Curitiba: Ibpex.

WERNKE, R. 2004. Gestão de custos: uma abordagem prática. 2. ed. São Paulo: Atlas.

YIN, R. K. 2001. Estudo de caso: planejamento e métodos. 2. ed. Porto Alegre:Bookma 